\title{
La narrativa quechua contemporánea en Perú como sistema: el inmenso caleidoscopio de la literatura latinoamericana
}

\author{
Marcia Muriel Manino \\ Universidad Nacional de Salta
}

Gonzalo Espino Relucé. Narrativa quechua contemporánea. Corpus y proceso (1974-2017). Pakarina Ediciones, Perú, 2019. 97 págs

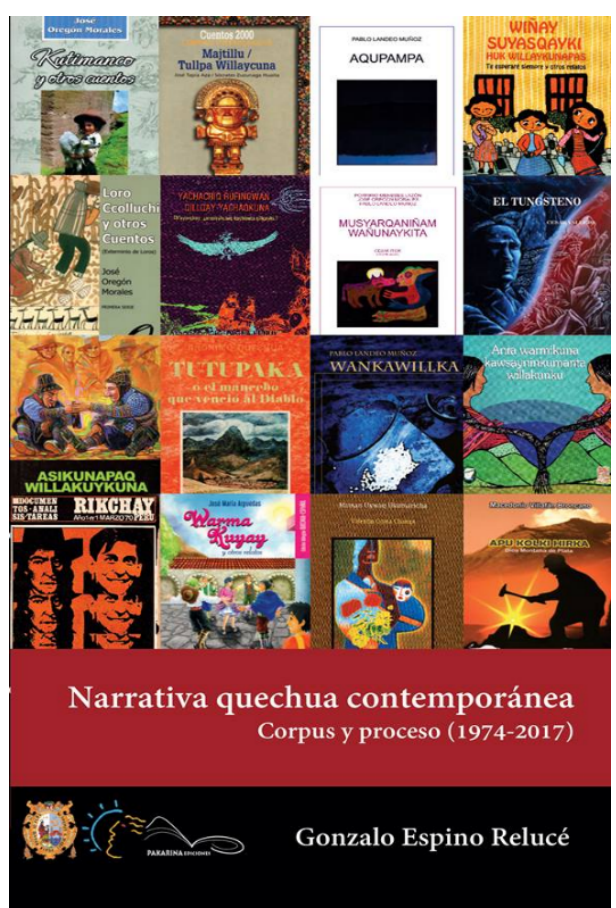

Gonzalo Espino Relucé dirige un grupo de investigación llamado Discursos, representaciones y estudio interculturales (EILA) y es en el marco de esas producciones donde nace Narrativa quechua contemporánea. Corpus y proceso (1974-2017).

El libro en cuestión da cuenta, crítica y detalladamente, de una cartografía de escrituras quechuas que inician en 1970 y que, por años, fueron invisibilizadas en el sistema literario latinoamericano. El estudioso moche emprende la tarea que Antonio Cornejo Polar (1989), en "Apéndice: La literatura peruana como totalidad contradictoria" propone como ineludible: pensar a la multiplicidad del escenario escriturario en Latinoamérica como una totalidad contradictoria. Para entender las producciones literarias que representan al plano social y cultural de nuestro continente se debe atender a los dinamismos que subyacen en el sistema. Estamos ante un movimiento y el libro de Espino Relucé es un fuerte e innovador aporte para ello.

José Carlos Mariátegui (1979), en Siete ensayos de la realidad peruana arguye que la literatura indigenista no puede dar una mirada real o acabada de la cosmovisión andina puesto que se trata de una escritura de mestizos. De ahí que sea indigenista y no indígena, última que tendrá su tiempo de manifestación. Sin embargo, Cornejo Polar (1994), en Escribir en el aire, arriesga que sí existe literatura indígena, lo que sucede es que la crítica no la acobijó en el centro del sistema literario. De hecho, el propio Espino Relucé da cuenta de estas últimas textualidades en el Perú sin perder de vista los planteos esenciales de los dos teóricos citados. En la introducción a Narrativa quechua contemporánea... coloca a las escrituras quechuas dentro de un segundo grupo, mientras que en el primero ingresarían las quechuas letradas que corresponden a las literaturas indigenistas de las que Mariátegui hablaba: "Ofrece (la narrativa quechua contemporánea) una literatura que en los años veinte del siglo pasado se anunciaba como aquello que vendría" (Espino Relucé, 2019: 9)

El libro del poeta y crítico moche está constituido por una introducción, seis capítulos, un epílogo y un anexo con dos relatos en quechua con su traducción al español. Es en la introducción donde se da cuenta del objetivo del estudio y el recorte de textos a considerar. Se propone indagar en textualidades que atraviesen la relación entre el espacio y la lengua con sus diferentes variantes del quechua: Ayacucho-chanka (Ayacucho), Cusco-Kollao (Cusco, Apurímac, Puno), Ancashino (Áncash) y, aunque escasas, las producidas en wanka (del norte y la amazonia). El autor afirma que la importancia de estas escrituras radica tanto en la impronta innovadora del idioma quechua como en el hecho de que se trata de una experiencia estética que explora variadas formas y estrategias narrativas. 
En el primer capítulo, titulado "Contextos y referentes teóricos" retoma la problemática de las tensiones que subyacen en la literatura andina. Antonio Cornejo Polar, Juan Carlos Mariátegui, Carlos García-Bedoya, José María Arguedas, Hugo e Iván Carrasco, Miguel Rocha y Claudia Rodríguez son pensadores ineludibles en los estudios de esta línea literaria que se divide en dos tramos. En primer lugar, el de la indefinición del proyecto nacional, que no consideró a la Amazonía, pero considera a la identidad desde la multiplicidad por la visibilización de lo andino. En segundo lugar, el que corresponde al último tercio del siglo XX hasta la actualidad del XXI, donde ingresan los textos literarios que importan en Narrativas quechuas contemporáneas...: ya no la de tipo indigenista, sino, más bien, la que se escribe en quechua, aimara o castellano andino. Este último grupo se caracteriza por la innovación y su capacidad expresiva de captar las subjetividades del mundo andino.

"Primeras narrativas quechuas" es el segundo capítulo. Allí, Espino Relucé analiza tres cuestiones en torno a la situación de estas escrituras en el sistema literario. En una advierte que, pese a que se produjeron potenciales reflexiones en torno a las narrativas quechuas, la crítica literaria es escasa, remitiéndose tan solo a dos estudiosos claves: Manuel Barquerizo y César Itier. En la segunda cuestión hace referencia a la tradición previa del corpus que propone: las manifestaciones orales recopiladas y transcriptas que se revelan en 1905. Acá son sustanciales los textos de José Flores, Teodoro Meneses, José María Arguedas y José A. Liro, quienes recopilan estos relatos de tradición oral. La última cuestión rescata la importancia de instituciones que abogan por la promoción de la escritura quechua.

En la tercera sección, "Narrativa quechua: características y corpus", el estudioso expone cinco líneas que permiten comprender el proceso de estas narrativas. La primera considera a la lengua en la que se produce y las dificultades que ello conlleva debido a la variedad lingüística. La segunda refiere al vínculo entre la lengua y la cultura. La siguiente línea indaga en los problemas que existen con el quechua y la necesidad de fortalecerlo para formar lectores. La cuarta atiende a las innovaciones que la figura del narrador adquiere en la ficción. Por último, la quinta línea sondea el modo en que los escritores abordan el impacto de la modernización y cómo con él diseñan una nueva cartografía. Además, en este capítulo Espino Relucé propone dos vías de caracterización: una en torno al referente lingüístico, relacionando espacio y lengua, y el otro en torno a la fecha de nacimiento de los autores y de publicación.

Los capítulos cuatro, cinco y seis abordan el análisis de escritores puntuales de narrativas quechuas. En "Las primeras tramas de narrativa quechua: Porfirio Meneres" encontramos las producciones de este escritor y algunas de José Tapia Aza y Orlando Santillán Romero. "Los quechuas de los ochenta: Sócrates Zuzunaga y Macedonio Villafán" ahonda en los dos autores nombrados e incorpora el análisis en torno a otros como Rufino Chuquimamani Valer, Gloria Cáceres Vargas y José Oregón Morales. En la última de las secciones, "Penúltimos narradores", son fundamentales las creaciones de Valentín Ccasa Champi, Ugo Carrillo, Óscar Chávez Gonzales, Domingo Dávila Pezúa, Junior Núñez Lefoncio, en general, y de Pablo Landeo Muñoz, de un modo particular.

La cartografía en la que ingresan estos escritores nos muestra que, como bien expresó Antonio Cornejo Polar, hay escritura indígena. Estamos ante textos escritos por quienes encarnan las colectividades andinas y logran tomar la palabra, apropiarse de la ciudad letrada, en términos de Espino Relucé.

Estas textualidades, afirma el autor de Narrativa quechua contemporánea..., se caracteriza por apoderarse de las diversas posibilidades que encontramos en la narrativa contemporánea. Permite, además, reconocer la cosmovisión andina ya no desde la mirada del letrado académico, sino desde la subjetividad que atraviesa a los propios escritores que visibilizan sus voces. La cuestión de la lengua es esencial puesto que es desde allí donde se experimenta. Pero la impronta innovadora también radica en el hecho de que "se ha convertido en una experiencia estética de la palabra atenta a conquistar a su lector, explora las diversas formas narrativas" (Espino Relucé, 2019:11) 


\section{Visitas alPatio

Este libro es un mapa de textualidades pertenecientes a la cultura quechua que están ingresando en el sistema de la literatura peruana como corpus definitivo. Espino Relucé pone acento en la necesidad de que este último se propague e inserte de forma definitiva como sistema dentro del inmenso caleidoscopio de producciones en Latinoamérica. 